\title{
Dermatofobrosarcoma Protuberans Care: Experience of the Dermatology Center of the Teaching Hospital of Treichville in Abidjan-Cote d'Ivoire
}

\author{
Kouame $\mathbf{k}^{1}$, Kassi $\mathbf{k}^{1^{*}}$, Kouassi KA ${ }^{1}$, Gbery $\mathrm{IP}^{1}$, Ecra $^{1}$, Ahogo $\mathrm{C}^{1}$, Allou $\mathrm{A}^{2}$, Sangare $\mathrm{A}^{1}$, Kouyate $\mathrm{M}^{3}$, \\ Yoboue $\mathrm{P}^{1}$ and Kanga JM ${ }^{1}$ \\ ${ }^{1}$ Department of Dermatology and Infectiology, training and research unit of medical sciences, university of Felix Houphouët of \\ Abidjan-Côte d'Ivoire \\ ${ }^{2}$ Dermatology center of the teaching hospital of Treichville \\ ${ }^{3}$ Anatomopathology department of the teaching hospital of Treichville
}

Received: October 25, 2017; Accepted: November 07, 2017 ; Published: November 22, 2017

*Corresponding author: Komenan kassi, MD, Department of Dermatology and Infectiology, training and research unit of medical sciences, university of Felix Houphouët of Abidjan-Côte d'Ivoire, PO Box: 21 BP 5151, Abidjan, Tel: 00(225)07047601; E-mail: siskakomlo@yahoo.fr

\begin{abstract}
Darier and Ferrand's Dermatofobrosarcoma protuberans is a local malignant skin tumor, characterized by high risk of recurrence. The treatment is mainly surgical. The prognosis is related to the quality of initial tumor excision. In Sub-Saharan Africa, few operated cases were reported. We have conducted a study on 34 cases, to show the importance of skin surgery in a dermatology department. The average age of our patients was 38 years. The main tumor locations were the limbs in $61.74 \%$ of cases and the trunk in $32.35 \%$ of cases. The tumor sizes varied from 2 to 28 centimeters in the majority of cases $(82,35 \%)$. The consultation time period was long, varying from 1 to 7 years. As a treatment, $26(76.47 \%)$ of 34 patients diagnosed were treated surgically. The tumor excision with $5 \mathrm{~cm}$ margins of tumor free was the only surgical technique used. The surgical defects were covered by skin grafts in $80.76 \%$ of cases. We reported 2 recurrence cases on the head $(7.69 \%)$. This case-series just reinforces the necessity to develop interventional dermatology, in particular skin surgery in the dermatology departments in black African countries to get efficient treatment at the right time.
\end{abstract}

Keywords: Dermatofibrosarcoma; Histology; Skin surgery; Recurrence; Dermatology;

\section{Introduction}

The Dermatofibrosarcoma (DFS) is a sarcoma developed from smooth tissues. It was firstly described in 1942 by both Jean Darier and Marcel Ferrand, therefore the given name: Dermatofibrosarcoma of Darier-Ferrand. It is a cutaneous sarcoma develops itself from fibrocytes of the dermis which express antigen CD34 on surface [1,2].

DFS usually evolves slowly and is painless. The initial tumor appeared as infiltrated and painless cutaneous area which may present a small discoloration. This tumor increases in volume and become large nodule which can turn in an important ulcerated and necrotic tumor. This tumor doesn't adhere to the under-structure of the skin (Figure 1). This tumor seems like others skin diseases (epidermal cysts, hypertrophic scar, keloid, dermatofibroma etc...)
DFS are mostly located on the trunk, followed by the lower limbs, and head and neck. DFS is a skin cancer which extends to metastasis only in 1-4\% ([11]-Jonathan Courtney).

The diagnosis is confirmed by histological examination by the presence of monotonic monomorphic spindle cells, arranged in storiform or "chevron" [11]. In almost all DFS (90\%), there is a genetic abnormality like the presence of characteristic unbalanced chromosomal translocation between chromosome 17 and $22[1,11]$.

Surgery remains the reference treatment of DFS. It is recommended to perform surgical excision with $5 \mathrm{~cm}$ of excision margins to reduce local recurrence rates $[6,11,12]$.

But, with the use of Mohs micrographic surgery and its derived techniques, high cure rate and low recurrence rate were reported, and associated with complete tumor resection and free tumor microscopic margins. These techniques allow to obtain good treatment results and to reduce excision margins $[2,6,9,10$ $12]$.

In sub-Saharan African, these techniques are not available. Here, we report our surgical treatment experience on series of 26 cases of DFS, using $5 \mathrm{~cm}$ surgical excision margins.

\section{Results}

Data from thirty four patients were included.

\section{Epidemiological Aspects}

The average age was 38 years (ranges from 8-58 years). There are more female: 19 (55.88" \%) than male: $15(44,11 \%)$, with a sex ratio (male/female) of 0,79 . DFS was mostly located on the lower limbs in $38,23 \%$ of cases (Figure 1), followed by the upper limbs in $23,52 \%$, and the trunk in $32,34 \%$ (Table 1 ). The time of consultation was mostly delayed and was so long (from 1 to 7 years). The average size of DFS was $11 \mathrm{~cm}$ as diameter varying from 2 to $28 \mathrm{~cm}$ in the majority of cases (28/34), the tumors length was important in $82,35 \%$ of cases. 
Dermatofobrosarcoma Protuberans Care: Experience of the Dermatology Center of the Teaching Hospital of Treichville in Abidjan-Cote d'Ivoire

\begin{tabular}{|c|c|c|c|}
\hline \multicolumn{2}{|c|}{ Clinical and Therapeutic Aspects } & \multirow{2}{*}{$\begin{array}{l}\text { Frequency } \\
\text { (n) } \\
2\end{array}$} & \multirow{2}{*}{$\begin{array}{l}\text { Percentage } \\
\text { (\%) } \\
5.88 \\
\end{array}$} \\
\hline Location & head & & \\
\hline & shoulder & 4 & 11.76 \\
\hline & fore-arm & 4 & 11.76 \\
\hline & $\begin{array}{l}\text { Abdomen- } \\
\text { thorax }\end{array}$ & 3 & 8.82 \\
\hline & Lower limb & 6 & 17.64 \\
\hline & bottom & 7 & 20.58 \\
\hline & back & 8 & 23.52 \\
\hline \multicolumn{4}{|c|}{ Treatment } \\
\hline \multicolumn{2}{|c|}{ Excision with $5 \mathrm{~cm}$ of margins } & 26 & 100 \\
\hline \multicolumn{2}{|c|}{ Mohs surgery } & - & - \\
\hline \multicolumn{2}{|c|}{ Vertical modified Technique } & - & - \\
\hline \multicolumn{2}{|c|}{ Directed Cicatrisation } & 4 & 15.38 \\
\hline \multicolumn{2}{|c|}{ Thine skin graft } & 19 & 73.07 \\
\hline \multicolumn{2}{|c|}{ Total skin graft } & 2 & 7.69 \\
\hline \multicolumn{2}{|c|}{ Lambeau cutané } & 2 & 7.69 \\
\hline \multicolumn{2}{|c|}{ Imatinibmesylate } & - & - \\
\hline \multicolumn{2}{|c|}{ Chimiotherapy } & - & - \\
\hline \multicolumn{2}{|c|}{ Radiotherapy } & - & - \\
\hline \multicolumn{4}{|c|}{ Follow up } \\
\hline \multicolumn{2}{|l|}{ healing } & 23 & 88.46 \\
\hline \multicolumn{2}{|c|}{ local recurrences } & 2 & 7.69 \\
\hline \multicolumn{2}{|c|}{ Metastases } & 1 & 3.84 \\
\hline \multicolumn{2}{|c|}{ Not treated (lost) } & 8 & 23.52 \\
\hline
\end{tabular}

\section{Therapeutic Aspects}

Twenty six patients of 34 diagnosed for DFS received surgical treatment. We only used surgical treatment with technique of 5 cm excision margins (Figure 2).

Histological examination for excision margins control was only done for $8(30.76 \%)$ post operative samples. Only two samples of margin control were positives. The surgical defects (Figure 3) were covered by fine skin graft in 19 cases (73.07\%), a directed cicatrization in 4 cases $(15,38 \%)$, a total skin graft in 2 cases (7.69\%), and a local skin flap in 2 cases $(7,69 \%)$ (Table 1$)$.

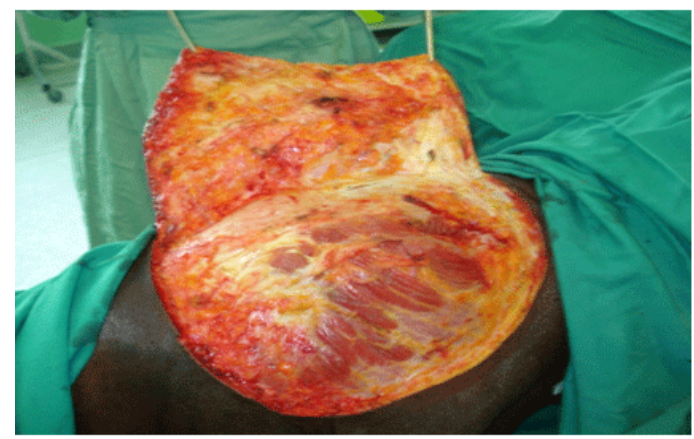

Figure 2: DFS of the bottom treated by $5 \mathrm{~cm}$ of excision margin

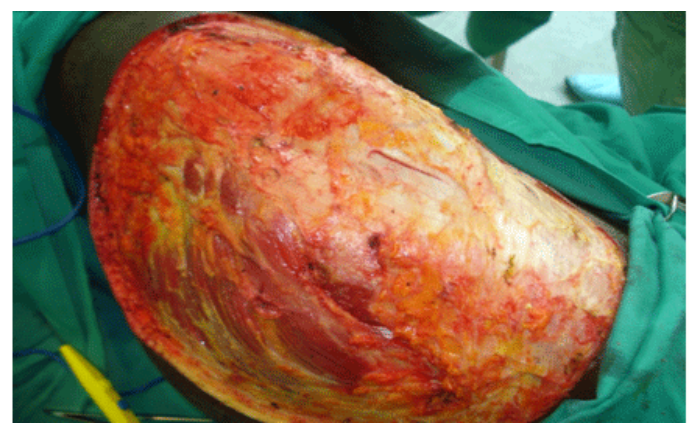

Figure 3: DFS of the bottom after surgical excision using $5 \mathrm{~cm}$ of margins

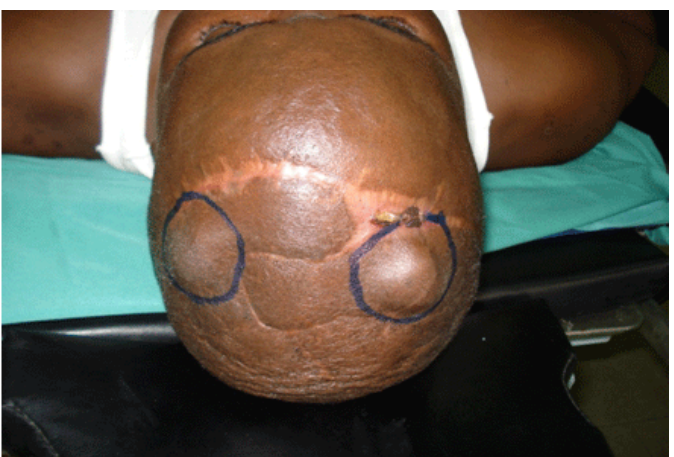

We did not report lymph node. But we found one case of secondary location, observed in one female patient. From the 34 patients diagnosed for DFS, we reported 3 recurrence cases treated surgically before their consultation.

Figure 1: Dermatofibrosarcoma (DFS) of the bottom before surgical excision

\section{Clinical Aspects}

Citation: kouame k, kassi k, et al. (2017) Dermatofobrosarcoma Protuberans Care: Experience of the Dermatology Center of the Teaching Hospital of Treichville in Abidjan-Cote d'Ivoire. Clin Res Dermatol Open Access 4(5): 1-4. DOI: http://dx.doi. 


\section{Course Aspects}

The twenty six patients treated by surgery were followed up about 1 to 2 years, and twenty three $(88,46 \%)$ patients were healed. We reported 3 cases of recurrences (figure 4), of them 1 case of general metastasis (3. $84 \%$ ), and 2 cases of local recurrences $(7,69 \%)$.

\section{Comments}

DFS is fibrous tumor of the skin which is between fibroma and saroma. This tumor represents about 0,1\%-1\% of malignant skin tumors [3].

The African scholars reported some case-series of 6 to 30 cases in 10 to 20 years, but they did not tell about treatment [4]. In our series, we reported almost the same number of cases, 34 cases in 7 years. The lack of knowledge on this disease by practitioners, and the lack of histopathological examination for its diagnosis on painless nodules, could explain it's the rarity in black Africa.

The sex-ratio of the disease vary in the literature depend upon the study population. In fact, some authors have reported that female is mainly affected, as we found in our case-series, but others have showed that male is mostly concerned [3-5].

The average age of our patients was 38 years. Patients with average ages between 28 and 47 were reported in the literature [3-5]. The elderly populations and infants are also affected by the disease, respectively a case in patients aged of 18 months and case in patients aged of 82 years were reported.

In 1989, SCHMOOKLER described a juvenile case of DFS, called fibroblastoma associated with giant cells, which appeared before 12th year of birth [4]. This observation was also reported in our series, with a case of DFS in an infant aged of 8 years. Some scholars observed some congenital cases mainly in blacks [6].

The diagnosis is difficult and mostly delayed in our practice setting. Because, this tumor look like cutaneous benign tumors; the absence of symptoms, and lack of histopathological examination could explain this [4]. This observation is in accordance with the average diameter of DFS more than $12 \mathrm{~cm}$ reported in our series corroborates. The trunk and the limbs were the most frequent locations of DFS in our case-series. Only, 02 cases of Head and neck were reported, but their treatment is difficult, because of the excision margins recommended. The classical evolvement of the disease is not always observed, because some cases start with one nodule or several nodules. These nodules have the same characteristics, as follow: they bleach under-pressure, evolve slowly, without a symptom, which explains the consultation delay [3]. The histopathological diagnosis of DFS is characterized by a fusiform cell proliferation in the dermis and the hypodermis surrounded by a structure made of collagen substances [2].

In developed countries, diagnosisis is made by immune histochemical examination which is positive with vimentin, but also for CD34 [2].genetic cell analysis shows the presence of numerous chromosomes including sequences from chromosome 17 and 22 or scarcely translocation $t(17 ; 22)[1,2]$. We did not perform these examinations, due to lack of materiel in our practice setting.

In our series, surgery was the main efficient treatment which showed its efficacy in tumor eradication, and recurrences' prevention [6,7]. The surgical procedure consisted of tumor excision with $5 \mathrm{~cm}$ of margins. The excision margins control were histologically free of tumor. The deep limits of the excision margin (fascia) were macroscopically free of tumor [6]. The aim of this surgical technique is to take of all pathological cells which are the cause of recurrences [6]. The histopahological examination brings the proofs of excision margin status: free or not free of tumor.

In our series, we reported 24 cases of excision margins free of tumors after surgical treatment. We did not observe recurrences after 2 years of follow up. But, we reported one case of metastasis on the forearm from a DFS of the bottom. If the classical excision margin of $5 \mathrm{~cm}$ was admitted, some scholars recommended reducing excision margins to $3 \mathrm{~cm}$ or less [8-10]. In developed countries, Mohs micrographic surgery is recommended more efficient for tumor margins control. In this technique the dermatologic surgeon stops excision when the tumor excision margins are free of pathological cells in microscope [7-10]. But, the lacks of materials don't allow to perform this surgical technique in our practice setting, where the treatment remains difficult and associated with recurrences $[1,3,4,8]$. It is the reason why the classical surgery with $5 \mathrm{~cm}$ of excision margin is performed. This recommendation contributes to reduce recurrences. It also needs additive reconstructive surgery to cover the soft tissue loss. In our series, we reported 21 skin grafts $(80,76 \%)$. These different reconstructive surgical techniques need qualified and trained health care practitioners as well as minimum medical equipments, that don't exist in Sub-Saharan Africa. Recurrences are the challenges of this disease. In fact, the frequency of the recurrences is related on the excision margins. Some scholars reported $40 \%$ of recurrences for $2 \mathrm{~cm}$ of excision margins, 10 to $20 \%$ of recurrences for $3 \mathrm{~cm}$ of excision margins and $1.75 \%$ of recurrences for $4 \mathrm{~cm}$ for excision margins [6]. In our series, we reported 3 cases of recurrences (2 locales and 1distance metastasis) from 26 cases (11.53\%) after of 2 years of follow up. In fact, for cephalic cases, it is very difficult to respect the $2 \mathrm{~cm}$ of excision margins. Currently, efficient and appropriate surgical techniques like Mohs surgery and related techniques are recommended. Out of surgery, Imatinib mesylate appears as new hope for metastasis cases [1]. Radiotherapy is also used in addition to surgery [6]. In our series, we hadn't and did not use these treatments.

\section{Conclusion}

The treatment of DFS remains the surgical treatment. The Mohs surgery and its derived are mostly indicated and used techniques in developed countries, but they are not performed in sub-Saharan Africa. The classical surgical treatment with $5 \mathrm{~cm}$ of excision margins remains the only treatment. The increasing knowledge of the disease and the good practice of dermatologic surgery in sub-Saharan Africa could allow adequate and early 
treatment. Therefore, it is necessary to create dermatological unites in all dermatology departments in Sub-Saharan Africa.

\section{References}

1. Bianchini L, Maire G, Pedeutour F. De la cytogénétique à la cytogénomique du dermatofibrosarcome de Darier-Ferrand (dermatofibrosarcoma protuberans) et des tumeurs apparentées. Bulletin du Cancer. 2007;94(2):179-189.

2. Gattoni M, Tiberio R, Angeli L, Bornacina G, Boggio P, Annali $G$, et al. Dermatofibrosarcome de Darier-Ferrand : traitement par la technique chirurgicale de Tübingen (31 cas). Annales de Dermatologie et de Vénéréologie. 2007;134(1):31-34.

3. Kasse M, Dieng A, Deme MC, Fall B, Drabo B, Timbely, et al. Dermatofibrosarcome de Darier et Ferrand A propos de 22 cas et revue de la littérature. Méd d'Afr Noire. 1999;46(4):222-227.

4. Traoré SS, Zida M, Baro FT, Boukoungou G, Goumbri OM, Sano D, et al. Le dermatofibrosarcome de Darier et Ferrand (DFDF). À propos de 7 cas au CHU de Ouagadougou, Burkina Faso. Bull Soc Pathol Exot. 2007;100(2):105-106.

5. Joucdar S, Kismoune H, Boudjemia F, Bacha D, Abed L. Les dermatofibrosarcomes de Darier et Ferrand - analyse rétrospective de 81 cas sur dix ans (1983-1994). Ann chirur Plast Esthé. 2001;46(2):134-140

6. Razafindrabe JAB, Ricard AS, Majouffre-Lefebvre C, Siberchicot F. Importance de la chirurgie dans le traitement des dermatofibrosarcomes de Darier et Ferrand. Revue Tropicale de Chirurgie. 2007;1:52-53.
7. Pachet C. Apport de la chirurgie micrographique dans la réduction des marges du dermatofibrosarcome de Darier-Ferrand : étude de 31 cas comparant l'exérèse large et la chirurgie micrographique et revue de la littérature. 2007.

8. Snow SN, Gordon EM, Larson PO, Bagheri MM, Bentz ML, Sable DB. Dermatofibrosarcoma protuberans: a report on 29 patients treated by Mohs micrographic surgery with long-term follow-up and review of the literature. Cancer. 2004;101(1):28-38.

9. Behbahani R, Patenotre P, Capon N, Martinot-Duquennoy V, Kulik JF, Pietteet F, et al. Vers une réduction des marges latérales dans les dermatofibrosarcomes de Darier et Ferrand? Étude rétrospective de 34 cas. Ann chirur Plast Esthé. 2005;50(3):179-185.

10. Guillot B. Comment optimiser le contrôle des berges d'exérèse en chirurgie carcinologique cutanée? Ann Dermatol Venerol. 2007;134:20-21.

11. Courtney J, Gorlick RG, Geller DS. Dermatofibrosarcome protuberant Par Jonathan Courtney, MD; Richard G Gorlick, MD et David S. Geller, MD Traduit en Français par Aurélie Dutor, PhD et Elodie Espesset Également disponible en Anglais et Polonais.

12. Kouame K, Komenan K, Kouassi KA, Kouassi YI, Gbery IP, Yoboue P, et al. Dermatofibrosarcome géant de la cuisse opéré sous anesthésie par intumescence. Nouv Dermatol. 2011;30:439-441.

13. Kumar L, Bhandari V, Singh S, Garg P, Kumar A. Giant dermatofibrosarcoma protuberans: A rare presentation over face. J Can Res Ther. 2015;11(4):1038. doi: 10.4103/0973-1482.139386

14. Larbcharoensub N, Kayankarnnavee J, Sanpaphant S, Kiranantawat K, Wirojtananugoon C, Sirikulchayanonta V. Clinicopathological features of dermatofibrosarcoma protuberans. Oncol Lett. 2016;11(1):661-667. 